\title{
MúSICA(S) E EDUCAÇÃO BÁSICA: PENSANDO PROCESSOS FORMATIVOS E AÇÕES PROFISSIONAIS NA UNIDOCÊNCIA*
}

\author{
Cláudia Ribeiro Bellochio \\ Universidade Federal de Santa Maria, Santa Maria, RS, Brasil \\ Eduardo Guedes Pacheco \\ Universidade Estadual do Rio Grande do Sul, Porto Alegre, RS, Brasil
}

\begin{abstract}
Resumo: Este texto busca pensar sobre a educação básica e a(s) música(s) na escola. Transversalizando a discussão são examinadas possibilidades formativas e de atuação de professores unidocentes licenciados em Pedagogia. Para isso, os autores buscam como problematizar com músicos, professores, compositores e pesquisadores sobre os entendimentos que conduzem, não só as práticas docentes destes profissionais, mas também as concepções sobre Arte e, em especial, sobre a Música na escola. Como se pensa o espaço da escola e o projeto de educação básica e suas relações com as músicas? Como a escola lida com as músicas ao elaborar e escolher suas concepções/relações com a infância, com a educação e, não menos importante, com a arte? Questões como estas conduziram a elaboração deste ensaio, o qual teve como principal objetivo problematizar acerca da educação básica, da escola, da formação e das práticas musicais de professores da educação infantil e dos anos iniciais do ensino fundamental.
\end{abstract}

Palavras-Chave: Educação básica. Música(s). Pedagogia. Unidocência.

Quando pensamos em educação básica, somos remetidos ao encontro com múltiplas formas de estar neste espaço: com professores, estudantes, conhecimentos. Nos remetemos aos espaços físicos da escola e suas condições estruturais, às escolhas realizadas para desenhar os modos/ jeitos de ensinar e aprender, e para lidar com a escola e suas dinâmicas.

\footnotetext{
* Artigo recebido em 4/11/2013 e aprovado em 24/1/2014.
} 
Por sua vez, participar do contexto escolar é se colocar frente às decisões, hierarquizações, tomadas de posição que atribuem sentido à educação e que impulsionam possibilidades de desenvolvimento humano, pautadas por trocas e criações. Assim, entendemos que a constituição de tempos e de espaços educacionais na escola só são possíveis pela presença de pessoas que assumem escolhas e pela atuação de professores, alunos, gestores, comunidade escolar em situações de mediação entre si e com os conhecimentos escolhidos e seus modos de serem trabalhados.

Em face do exposto queremos pensar, neste momento, no que é muito comum na escola, mas, ao mesmo tempo, tão ausente nas elaborações e nas práticas pedagógicas dos professores. Pensamos nos sons da escola, em suas músicas, nos sons musicais de professoras e professores que atuam na educação infantil e nos primeiros anos do ensino fundamental, e em suas relações no cotidiano profissional, construído, principalmente, na docência para e com as crianças.

Não resumimos nossos pensamentos ao cantar com as crianças ou ao autoritarismo de repertórios pensados/escolhidos como próprios para o espaço escolar. Valorizamos práticas musicais de cantar como genuína forma da infância. Salientamos as imensas contribuições das músicas de percussão no fazer musical da escola, com suas variações, que vão das notas musicais percutidas com o corpo às músicas tocadas com tambores e outras possibilidades. E quando pensamos na soma das vozes com as percussões, escutamos possibilidades da música na escola. Mas, não descartamos outras formas da(s) música(s) para e na escola: ruídos, desafinações, contratempos... Outros sons e outros silêncios.

Para pensarmos, propomos uma cena. Uma cena que é comum na escola e que traz outros componentes para nossa audição. Componentes mediados e mediadores da vida da escola que se misturam com professores e seus processos constitutivos da docência, de ordem formativa e de ordem da ação profissional.

\section{A ESCOLA, SEUS SONS E A PEDAGOGIA}

É horário de entrada na escola, muitos sons ajudam a compor esta imagem. Conversas, batidas de pés no chão, que ora correm e ora caminham, músicas dos fones de ouvidos ou dos pequenos aparelhos de som carregados na palma da mão, celulares por todos os lados compõem uma sinfonia ruidosa. São falas, gritos, batidas de pés que andam e correm, brincadeiras que têm sua existência interrompida pelo início das aulas, momento em que toda a escola passa a experimentar uma nova composição sonora. Esta não deixa entrar 
nada que possa intervir na organização escolar, mas estudantes insistem, às escondidas, em continuar suas sonorizações.

Aos poucos, polirritmias e polimelodias são substituídas pelas monomelodias das vozes professorais que, não menos do que os alunos, deixam suas músicas do lado de fora da sala de aula. Assim, perguntamos: os sons da vida não cabem na escola? Ou melhor, quais são os sons que cabem nas salas de aula? Entendendo o início da aula como a marca de um filtro que decanta as sonoridades que ajudam a compor o espaço escolar, nos perguntamos: Como este filtro lida com a música dos seus alunos? E com as músicas dos professores e professoras deste espaço escolar? Como a escola lida com as músicas ao elaborar e escolher suas concepções/relações com a infância, com a educação e, não menos importante, com a arte?

As questões acima apresentadas servem de referência, pois a principal força das perguntas aqui feitas não está condicionada por uma noção de verdade, mas sim pelo desejo de que estas perguntas indiquem caminhos, possibilidades de realização musical na escola e, ao mesmo tempo, de gerar outras perguntas.

Somados aos sons da escola, queremos também pensar nas músicas ligadas à prática docente dos professores licenciados em Pedagogia. E para que possamos percorrer algumas pistas, tomamos como ponto de partida alguns pontos da formação destes profissionais dos primeiros anos da educação básica.

No plano das políticas nacionais brasileiras, as diretrizes da Pedagogia orientam-se pelo princípio da docência como um dos fundamentos centrais da formação de professores de Educação Infantil e Anos Iniciais do Ensino Fundamental. Segundo essas diretrizes,

o curso de Licenciatura em Pedagogia destina-se à formação de professores para exercer funções de magistério na Educação Infantil e nos Anos Iniciais do Ensino Fundamental, nos cursos de Ensino Médio, na modalidade Normal, de Educação Profissional na área de serviço e apoio escolar e em outras áreas nas quais sejam previstos conhecimentos pedagógicos. (BRASIL, 2006)

Quando trazemos a formação de professores para discussões sobre práticas formativas, muitas são as interpretações. Parece evidente que uma das decorrências interpretativas, e projetivas, se deve ao fato de que"a porosidade da palavra 'formação' exige cuidado para que não se caia em uma discussão que a banalize e se esvazie de sentido" (Fernandes; CunHA, 2013, p. 52). Assim, pensar a formação musical na Pedagogia é também mirar a complexidade do processo formativo que, por natureza, é de ordem da teoria e da prática. 
É pensar que a complexidade da ação profissional de um professor dos primeiros anos da escola está imersa na potencialização de formas e modos que impulsionem o modo de pensar e de elaborar conhecimentos dos estudantes.

Passando a tomar a Pedagogia como curso formador de professores, trazemos a educação musical para dialogar, problematizar e entender algumas relações que temos pensado entre a música, a formação de professores não especialistas nesta área, mas especialistas no ensino dos primeiros anos da educação básica e a unidocência/monodocência/multidisciplinaridade. Professores estes que estão na escola e que convivem largamente com os processos de ensinar e aprender de crianças que iniciam sua escolarização, seu aprendizado formal, mediados por diversos conhecimentos, dentre eles os geográficos, os plásticos, os linguísticos, os matemáticos e os musicais.

Somada aos aspectos da formação de professores e aos aspectos políticos que orientam o curso de Pedagogia, a política educacional brasileira também apresenta um contexto para a música na escola de educação básica. Esse contexto fundamenta-se na alteração do artigo 26 no parágrafo $2^{\circ}$ da LDB' que dispõe: "o ensino de arte, especialmente em suas expressões regionais, constituirá componente curricular obrigatório, nos diversos níveis da educação básica, de forma a promover o desenvolvimento cultural dos alunos" (BRASLL, 1996).

Após um movimento articulado entre músicos, educadores musicais e representantes políticos do país foi sancionada, pelo presidente da República, a Lei n. 11.769/08, que modificou o artigo 26 da LDB, acrescentando-lhe o parágrafo $6^{\circ}$, através do qual se determina: "A música deverá ser conteúdo obrigatório, mas não exclusivo, do componente curricular de que trata o parágrafo 20" (BRASIL, 2008), ou seja, "o ensino da arte".2

Segundo essa legislação, a música deverá estar presente na educação básica; dizendo de outra forma, oferecer música na educação infantil e nos anos iniciais do ensino fundamental também é dever legal. Como as professoras que atuam nestes níveis escolares são unidocentes/monodocentes/ multidisciplinares entendemos que também estarão implicadas em trabalhos com música na escola, para além de práticas resumidas a cantar algumas canções em dias de festa ou a reproduzir repertórios musicais "próprios" como aqueles aqui já mencionados. Por suposto, existem possibilidades e limites nessa atuação (ver Bellochio, 2000, 2001, 2007, 2008; Bellochio; Figueiredo, 2009) que também precisam ser discutidos no contexto maior que é ensinar e aprender nos primeiros anos da educação básica, quer na educação infantil quer nos anos iniciais do ensino fundamental. 
Recentemente, a Resolução CNE/CEB de n. 7/2010, que fixa Diretrizes Curriculares Nacionais para o Ensino Fundamental de 9 (nove) anos, orienta, em seu Artigo 31, que

[...] do $1^{\circ}$ ao $5^{\circ}$ ano do Ensino Fundamental, os componentes curriculares Educação Física e Arte poderão estar a cargo do professor de referência da turma, aquele com o qual os alunos permanecem a maior parte do período escolar, ou de professores licenciados nos respectivos componentes. (BRASIL, CNE, 2010)

No parágrafo $2^{\circ}$ do mesmo artigo orienta-se que

[...] nos casos em que esses componentes curriculares sejam desenvolvidos por professores com licenciatura específica (conforme Parecer CNE/CEB n. $2 / 2008$ ), deve ser assegurada a integração com os demais componentes trabalhados pelo professor de referência da turma. (BRASIL, CNE, 2010)

Tais questões são vinculadas às orientações profissionais e também às políticas públicas do país, que necessitam ser somadas às nossas formas de entender e projetar a música na formação de professores e em sua prática na escola.

Nesta discussão acerca da formação em arte/música cabe considerar a impossibilidade de se pensar que a formação musical na Pedagogia seja da mesma ordem da formação de um músico, ou de um bacharel em música, por exemplo. $O$ profissional unidocente tem sua atividade profissional como professor de referência de uma turma de crianças e, portanto, sua formação, teórica e prática, deve estar voltada a este universo que é abrigado e impulsionado no espaço da escola. Se, por um lado a formação não deve restringir-se à formação instrumental, técnica para trabalhar com música na sala de aula, por outro, não pode negar sua necessidade.

Desta forma, ao assumirmos a música como arte, que compõe suas obras a partir das sonoridades que compõem a vida, e que por esta razão, não ficam fora da sala de aula, mesmo com a tentativa realizada pelas escolhas pedagógicas que buscam filtrar o viver, este trabalho pergunta como a música pode compor as ações destes professores e professoras que atuam na Educação Infantil e nos Anos Iniciais do Ensino Fundamental, sem deixar de considerar que as possibilidades de trabalho exercidas pelos professores e professoras pedagogos têm particularidades no que diz respeito à criação e ao desenvolvimento de situações de ensino e aprendizagem que envolvam música na sala de aula.

Discutir a presença da música no contexto escolar a partir das ações de profissionais unidocentes significa ampliar as possibilidades de relação 
com o fazer musical, mesmo que estes espaços, também, possam contar com a presença de um professor especialista em Educação Musical. É este profissional que tem maiores chances de realizar as conexões, os atravessamentos entre as áreas de conhecimento que sua prática docente conduz nos processos vividos nos espaços escolares. Assim, mesmo com a presença de um educador musical, é o professor unidocente o responsável por criar relações entre os diversos conhecimentos que por eles são apresentados e coordenados nos processos de ensino e aprendizagem. Ainda, caso os espaços educativos não possam contar com o educador musical, tendo como base uma formação adequada, é o professor unidocente quem pode possibilitar que situações de educação musical sejam experimentadas pelos estudantes.

MúSICA(S) NA ESCOLA

A escola, com seu projeto de Educação Básica, existe e é para atuar profissionalmente nela que são formados professores. No Brasil, a escola é o espaço atual de edificação do projeto da Educação Básica da Lei de Diretrizes e Bases da Educação Nacional (Lei n. 9.394/96). O Art. 22 da referida Lei expõe que "a Educação Básica tem por finalidade desenvolver o educando, assegurarIhe a formação comum indispensável para o exercício da cidadania e fornecerIhe meios para progredir no trabalho e em estudos posteriores" (BRASIL, 1996). O texto é amplo e dele emanam muitas leituras, as quais não serão objeto de análise neste artigo, que apresentará apenas algumas reflexões nos limites de um texto de orientações políticas.

A Educação Básica é um nível da educação nacional que congrega, articuladamente, as três etapas que estão sob esse conceito: a educação infantil (creche e pré-escola), o ensino fundamental ( $1^{\circ}$ ao $9^{\circ}$ ano) e o ensino médio ( $1^{\circ}$ ao $3^{\circ}$ ano). Importante lembrar que a Escola como instituição, ao lado da família, sofreu imensas transformações na modernidade passando a representar um "modelo socialmente aprovado e definido" (CAMBI, 1999, p. 204) para ensinar formalmente, organizando conhecimentos e avaliando processos de aprendizagem, aos seus estudantes.

A escola se faz necessária para abrigar e mediatizar o projeto educacional, imprescindível para uma sociedade autenticamente moderna. A especificidade do trabalho pedagógico exige uma institucionalização de meios que vinculem educadores e educandos. A escola não pode ser substituída pelos meios de comunicação de massa, toda relação pedagógica depende de um relacionamento humano direto. Toda a situação de aprendizagem, para ser educacional, não basta ser tecnicamente operativa, precisa ser pedagógica, ou seja, relaciona pessoas diretamente entre si. (SEvERINo, 2009, p. 83) 
A escola, lugar dedicado a oferecer a possibilidade de entrar em contato com conhecimentos, validados pela humanidade, e como forma de promover a inserção social, também é compreendida como espaço de exercício e apropriação de regras de convívio e de desenvolvimento de seus estudantes. Nos últimos tempos, esta formação tem sido recheada com tentativas de tratar o desenvolvimento humano a partir de uma perspectiva mais integral, em que o corpo deixa de ser um simples suporte para o exercício da razão, mas sim componente inseparável dos processos de elaboração do pensamento.

Aprender, pensar e criar não acontecem sem que o corpo esteja envolvido. Esta escola, estes ideais, que nascem com a aurora de um pensamento calcado no desejo de ter a vida conduzida pela razão, são elementos fundadores desta instituição. No entanto, a partir de provocações feitas por filósofos como Nietzsche (2007), o que propõe trocar os valores da razão pela sensações produzidas pela Arte como modo de conduzir a vida (ou seja, estetizar o viver), e como Spinoza (2007), que, num passado mais distante, coloca o corpo como traço indispensável para a produção do pensamento, a escola e as propostas educacionais têm experimentado criar novas alternativas para as ações educacionais. Tomando a provocação feita por Corazza (2008), que problematiza os modelos de pesquisa, que toma os fatos como critério para sua realização (empirismo), a razão como guia que proporciona um encontro entre o racional e a realidade (racionalismo), questiona a pesquisa que atribui exageros afetivos ao pesquisador e pesquisados, o foco nas subjetividades, os indivíduos, no Eu, nas investigações carregadas de nostalgia, na busca por algo a ser reconstituído (romantismo), propondo que o espírito moderno ceda espaço para novas ideias em educação, buscamos ampliar estas proposições para o contexto onde professores e professoras pedagogos exercem suas atividades profissionais, desejando que novas alternativas possam surgir quando pensamos em práticas educativas. Propomos curiosidade, para que os espaços educativos da escola possam, também, ser lugares de experiências que ultrapassem o empirismo, o racionalismo, e o romantismo, e para que novas ideias possam ser produzidas no cotidiano das ações; não só da educação musical, mas também da escola com um todo.

Esta perspectiva amplia o desenvolvimento proposto na educação para além dos modelos que desconsideram o corpo, a estética, as sensações e a arte como forma de conhecimento. Os pensamentos não quantitativos, os conhecimentos não organizáveis a partir de uma perspectiva da racionalidade, e as provocações feitas pela arte, têm sido convocados para participar deste processo formativo. Com estas novas cores e novos sons, a atuação 
dos docentes passa a ganhar novas texturas. Nossa escolha é exaltar a cor que coloca a atuação docente, também, como um lugar de transformação do próprio professor. Desta forma, ensinar música, trabalhar com música no cotidiano docente dos professores de educação infantil e anos iniciais do ensino fundamental, diz respeito às possibilidades de mudança que o próprio docente pode experimentar ao propor situações de ensino e de aprendizagem. Diz respeito, sobretudo, a outras e novas escutas de seus estudantes e do mundo da escola de educação básica. Não se trata de realizar uma comunicação entre conhecimentos e informações, mas, sim, de propor relações nas quais tais conhecimentos e informações possam tornar-se desestabilizadores das nossas condições de vida. É dessa forma que Foucault (2006, p. 294) nos convida a pensar, propondo que

[...] o que constitui o interesse principal da vida e do trabalho é que eles Ihe permitem tornar-se diferente do que você era no início. Se, ao começar a escrever um livro, você soubesse o que iria dizer no final, acredita que teria coragem de escrevê-lo? O que vale para a escrita e a relação amorosa vale também para a vida. Só vale pena na medida em que se ignora como terminará.

O que vale para a escrita, para a relação amorosa, para a prática pedagógica, também vale para a vida e para a compreensão da escola. Mesmo que esta abarque um projeto moderno, disciplinar e com orientações curriculares, não podemos torná-la igual todos os dias e todos os anos. A escola pode e deve ser modificada pelas formas e modos pelos quais o encontro entre conhecimento, professores e estudantes vai sendo constituído. Portanto, escolhemos entender a atuação docente, a vida dos alunos e os conhecimentos que circulam na escola não como lugares de amarrações ou fixações identitárias de professores, de estudantes e de conhecimentos. Essa compreensão implica pensar a escola e seu projeto de educação básica como lugar no qual a experimentação de si acontece pelo exercício de propor ao outro (aluno), mediado pelos saberes disciplinares e pelo diálogo, situações onde os conhecimentos ali tratados não sejam mais que alimento para o exercício de pensar e, sendo assim, exercício de produção de conhecimentos que potencializam o desenvolvimento dos estudantes.

Um dos espaços da escola de grandes encontros é a sala de aula. Este é o lugar onde o professor, ao propor o desenvolvimento dos alunos, mediado pelos saberes programados, é acometido pelo exercício docente. Portanto, por mais que estes saberes sejam da ordem do disciplinar, não são submetidos ao repasse, mas às trocas e aos problemas que deles derivam, quando em interface com os estudantes e seus conhecimentos já internalizados. 
Assim, ensinar é colocar em dúvida as certezas sobre o que se está ensinando, é buscar que, ao término de uma aula, o responsável pela coordenação dos trabalhos propostos saia tão transformado por esta experiência quanto os alunos que por ela passaram. Deleuze (1992) nos lembra que não se ensina sobre aquilo que se sabe, mas sim sobre aquilo que desejamos aprender.

A escola não se configura como entidade das certezas, mas sim como espaço para as dúvidas. Ensinar sobre aquilo que desejamos aprender demanda que os processos de ensino e aprendizagem sejam desenhados a partir da perspectiva de que o professor, que está propondo esta situação, também está aprendendo com os alunos e com os conhecimentos mediadores. A sua curiosidade é ferramenta pedagógica, é dispositivo didático para possibilitar que outros possam aprender. E para isso, no projeto de educação básica que pensamos para a escola, as perguntas passam a ocupar lugares mais destacados que as respostas. Criar dúvidas e questionamentos como caminho para o desenvolvimento é entender que este processo não acontece pela acomodação, mas sim pela deformação e transformação das percepções sobre mundo, ou, ainda, pela criação de novas possibilidades de percepção. Trazendo para o campo da música na escola, cabe abrir espaços para os sons que ainda não existem como música, mas que podemos transformar e trazer ao universo da construção musical dos estudantes, desde a educação infantil. Para isso, propomos que o entendimento sobre a música, enquanto arte, ultrapasse as ideias vinculadas à organização sonora. Escolhemos entender a música como

[...] algo que invade o lugar do brincar, de fabular, de namorar, de morar. A música não se cala, ela carrega uma resistência que não pode ser interrompida. Transborda. Ressoa. Assimetria inevitável e necessária que interliga e comunga ludicidade para afirmar que o princípio é a existência de sons [e silêncios]. (LINo, 2008, p. 24)

Barros (2003), por meio do seu livro Memória inventada: a infância, compartilha com seus leitores suas sensações sobre a infância. Convida-nos a sentir este tempo da vida percebendo os infantis como aqueles que têm alegria em (des)nomear as coisas, trocar de lugar as ordens estabelecidas, e da mesma forma compartilham sua felicidade em encontrar palavras a que novos sentidos possam ser atribuídos. Propomos estes valores para invadir nosso entendimento sobre a música, com seus sons e silêncios, uma expressão de arte que não vista as roupas das palavras de ordem. Músicas que possuam a leveza que lhes permita experimentar velhos e novos sentidos, que estejam abertas para o encontro com o novo, mesmo 
que este novo tenha sido criado no passado. Nossa intenção é encontrar, pesquisar, criar, ouvir e sentir músicas que provoquem nossa curiosidade. Propomos que professores pedagogos possam experimentar a ousadia das crianças que tomam para si as músicas dos outros, que fazem dessas obras suas composições, embaralhando, misturando, recriando aquilo que passa a ser do seu domínio (LINO, 2008). Desse modo, as fronteiras estabelecidas pelo tempo, pela geografia, pelos gêneros, pelas classes sociais perdem suas forças enquanto traço de delimitação de territórios, de identidades para, através das suas especificidades tornarem-se elementos das criações musicais. E poderemos, talvez, tomar emprestado das crianças esse jeito de recriar as músicas no cotidiano da escola, reinventando não só as sonoridades, mas também nosso entendimento sobre o espaço em que os professores e professoras pedagogas estão atuando.

No entanto, cabe ressaltar novamente que esta escolha não significa abrir mão das velhas percepções, conhecimentos e práticas, como cantar e percutir na escola, imprescindível forma de fazer música das crianças; nem mesmo abrir mão de antigas sensações ou proposições criadas em um passado distante ou próximo. Assim, não se trata também de negar a importância e a existência da escola, nem de projetos como o da formação de professores para a educação básica na escola. Ao pensar a música na escola e para a escola, como fazemos neste texto, temos em mente a necessidade de utilizar repertórios musicais existentes, mas também enfatizamos a necessidade de novos sons e novas audições.

Assumimos que as possibilidades de mudança de si estão ligadas à relação com percepções já dadas. Stravinski (1996), compositor russo, ao falar da sua relação com as obras do passado e de outros compositores, nos diz sobre a necessidade de se aproximar das músicas já criadas. É importante que novos compositores estejam muito próximos do que já foi criado, pois tal proximidade possibilita experimentar como estas pessoas exercitaram seu pensamento no processo de composição em música. Entretanto, estar o mais perto possível do que já foi criado convida os novos compositores a não criarem novamente o que já foi inventado. Assim, o entendimento sobre a ação docente que estamos propondo atribui valor ao conhecimento dado assim como o corpo necessita de alimento para viver. É a partir da relação com o que já foi dito que novas coisas poderão ser proferidas. Necessário se faz nutrir as possibilidades de pensamento não com doutrinas e dogmas, mas a partir da degustação das ideias apresentadas por biólogos, físicos, historiadores, literatos, músicos, matemáticos e todos aqueles que produziram pensamentos e constituem o arsenal de conhecimento escolhido para ser tratado na escola. 
MúSICA(S) - PEDAGOGIA E UNIDOCÊNCIA

Aqui, faz-se necessário a reapresentação das nossas intenções, colocando a questão: como a música compõe, enquanto arte, as ações docentes dos professores licenciados em Pedagogia? No entanto, nesta reapresentação acrescentamos o termo "arte", com a intenção de reconhecer nesta palavra "mais do que um divertido acessório, do que o tintinar de guizos que pode muito bem dispensar ante a seriedade da existência" (NIETZSCHE, 2007 , p. 26). As palavras do filósofo alemão, mesmo que proferidas em outro século, carregam grande quantidade de verdade. Sua crítica diz respeito à forma como a modernidade trata a música no poente de um novo tempo da humanidade; ou seja, como um utensílio, como mais um apetrecho que serve para adornar e trazer certo brilho a uma vida que necessita de razões para ser conduzida.

A música, em nosso tempo, "tornou-se um simples ornamento que permite preencher noites vazias com idas a concertos ou óperas, organizar festividades públicas ou, quando ficamos em casa, com a ajuda dos aparelhos de som, espantar ou enriquecer o silêncio criado pela solidão" (HARNONCOURT, 1998, p. 13).

Ambos os pensadores, ao discutirem os lugares e papéis que a música assumiu na vida moderna, o fazem com ares de crítica. Segundo o entendimento dos mesmos é preciso atribuir à música o status de forma de pensamento, possibilidade de intervenção e criação da realidade. Essa concepção coloca no lugar da comunicação e do entendimento a relação estética como forma de atuação humana. Mais do que isso, ao atribuir à música este papel, também estão sendo propostas formas de entendimento sobre a vida. E para isso, o que tentam realizar, é criar um lugar de menor passividade para esta "arte". Suas proposições passam por não atribuir ao fazer musical um lugar coadjuvante no viver. Música é mais do que pano de fundo para as atividades humanas. É preciso fazer com que estas ideias possam invadir os espaços escolares, e que a música ocupe papel mais significativo do que preencher os ambientes nas horas de descanso e, ou de pretensa tranquilidade; que seja propulsora de pensamentos, ferramenta de desenvolvimento humano pautado pelo viés estético.

Como argumentamos neste texto, a escola e o seu projeto de educação básica, com as dinâmicas de relação entre professores, estudantes e conhecimento não é algo que possa estar separado da vida, também são vida. Assim, não precisamos de muito esforço para perceber que a música no contexto da escola também tem ocupado lugares como os discutidos por Nietzsche (2007) e Harnoncourt (1998). Ou seja, a utilização da música 
no contexto educacional muitas vezes tem prescindido dos seus aspectos artísticos e estéticos atribuindo-Ihe um espaço destinado a fazeres não musicais, isto é, propondo a utilização da música a partir de questões que descartam o pensamento artístico e, em especial, suas possibilidades enquanto ferramenta de desenvolvimento humano. Assim, é importante assumir que a arte é uma forma de pensamento, de atuação; está atrelada à vida, às escolhas políticas, sociais e econômicas, não por estes índices terem força de determinação, mas sim por compor um conjunto de escolhas, gostos, medos, relações e tantos outros aspectos que ajudam a elaborar a realidade dos seres humanos. Nesse contexto, a música é um movimento da expressão humana, não na condição de representação da humanidade, mas sim como a própria humanidade, modo de atuação e forma de existência no contexto atualizado da realidade. Tomando estas ideias como referência é possível entender que a presença da música no contexto escolar assume um papel de grande importância. Se defendemos a relação com conhecimentos já validados, como alimento para o desenvolvimento proposto no contexto escolar, excluir a música das ações educacionais é negar aos alunos e alunas a oportunidade de, através da educação formal, vivenciar mais um canal de relação com esta arte.

A presença da arte no contexto escolar, no caso deste trabalho, a presença da música, demanda atenção especial a alguns aspectos. Como tratar de uma forma de pensamento pautada pela força estética dentro de um contexto cunhado pelo exercício da razoabilidade? Como o pensamento artístico pode, em composição com o exercício proposto nas relações com o conhecimento exercitado no contexto escolar, contribuir com o desenvolvimento humano buscado nas ações educacionais da educação básica?

A nossa escola entende o pensamento estético, a inefabilidade da arte como elementos para o exercício da relação com o mundo no qual estamos inseridos? Dentro do desenho apresentado por este conjunto de questões, cabe lançar nossos olhares para a formação em educação musical de professores pedagogos. Profissional, por excelência, de atuação multi e interdisciplinar, é responsável pela organização e coordenação de ações educacionais que envolvem um conjunto de saberes e conhecimentos. Daí a designação de "unidocência", projetada para a complexidade de sua atuação profissional e não reduzida à singularidade da expressão "uni". A sua prática não está pautada por separações. Fazem parte do seu domínio números, histórias, letras, elementos químicos etc. No entanto, como a arte é arranjada, não só nas suas intenções como professor, mas na sua formação? Responder a esta pergunta é também indagar sobre como a formação de professores 
pedagogos escolhe entender e se relacionar com o conhecimento produzido pela humanidade. Este trabalho busca intersecção com aqueles projetos de formação que optaram por se desfazer das hierarquias cunhadas pela vontade moderna.

Buscamos outras formas de relação com o conhecimento que não aquelas cunhadas pela supremacia da razão, pelo autoritarismo da cognição racional e da dominação dos entendimentos psicologizantes que minam e dominam, muitas vezes, o pensamento da área educacional. Escolhemos relações rizomáticas com a realidade (DeleuzE; GuATtARI, 1995). Números não são mais importantes que linhas, fórmulas não tem mais valor que desenhos. $\mathrm{O}$ que há são as diversas possibilidades de intervenção no mundo. Mais do que isso, o que existe são as múltiplas possibilidades de intervenção nesse mundo. Assim, estudar sobre a matemática que estão imbricadas na engenharia dos prédios que habitamos tem tanto valor quanto conhecer a química que invade diariamente nossa mesa através dos agrotóxicos na nossa alimentação. Da mesma forma, possui grande importância adentrar nas páginas dos livros de história, de literatura, das músicas dos tambores africanos, das melodias da música europeia, das canções de ninar de diferentes tempos e lugares da cultura humana. É através desta perspectiva que propomos lançar nossa atenção para a música no contexto escolar, olhar este escoltado pela vontade; que professores pedagogos possam juntar suas ações à música.

Falar sobre música no contexto escolar, tendo como foco a formação musical e pedagógico-musical de professores pedagogos, também se apresenta como uma crítica. Não se trata de uma denúncia, nem de apontamentos acusatórios. Ao afirmarmos, através dos pensamentos aqui propostos de pensadores, músicos, filósofos e professores escolhidos para ajudar a construir nossas ideias, também estamos realizando uma crítica, num movimento que se apresenta como atenção e proposição. Dessa forma, como já dito nas palavras iniciais, este texto também é um exercício para os próprios autores, que encontram alimento na possibilidade de propor uma escola mais recheada de música, não como forma de anunciar um novo caminho a ser seguido, mas como vontade de criar tensão, desestabilização nos lugares tidos como naturais. Assim, ao tratar da música no contexto escolar, ao chamar para esta discussão a formação de professores pedagogos, estamos propondo pensar a educação; já que decidir ou não sobre a forma e a qualidade da presença da música não diz respeito somente a esta forma de expressão, mas está diretamente ligada ao conceito, às escolhas e às concepções e práticas que assumimos em relação a esta instituição. 
MUSIC AND ELEMENTARY EDUCATION: THINKING OUT FORMATIVE PROCESSES AND PROFESSIONAL ACTION IN GENERALIST TEACHING

ABSTRACT: This text reflects on elementary education and music in the school. It transversalizes the discussion, and deals with formative and professional possibilities for generalist teaching by Pedagogy graduates. To do so, the authors problematize with musicians, teachers, composers and researchers the understanding which underlies not only their teaching practices but also their conceptions on Art and especially Music in the school. How is the role of the school and the elementary education project and its relation to music understood? How does the school deal with music when drawing up and choosing its conceptions/relations with childhood, education and, last but not least, Art? Questions such as these are the background to this essay which sets out to discuss elementary education, the school and the formation and music practices of elementary and middle school teachers.

KEY WORDS: Elementary education. Music. Pedagogy. Generalist teaching.

\section{MÚSICA(S) Y EDUCACIÓN BÁSICA: PENSANDO PROCESOS FORMATIVOSY ACCIONES PROFESIONALES EN LA UNIDOCENCIA}

RESUMEN: Este texto busca pensar sobre la educación básica y la(s) música(s) en la escuela. Transversalizando la discusión, se discuten las posibilidades de formación y de actuación de profesores unidocentes licenciados en Pedagogía. Para esto, los autores buscan cómo problematizar con músicos, profesores, compositores e investigadores sobre los entendimientos que conducen, no sólo las prácticas docentes de estos profesionales, sino también las concepciones sobre Arte y, en especial, Música en la escuela. ¿Cómo se piensa el espacio de la escuela y el proyecto de la educación básica y sus relaciones con las músicas? ¿Cómo la escuela lidia con las músicas al elaborar y escoger sus concepciones/relaciones con la niñez, con la Educación y, no de menor importancia, con el Arte? Cuestiones como esas conducen a la elaboración de este ensayo, el cual tiene como principal objetivo problematizar acerca de la educación básica, de la escuela, de la formación y de las prácticas musicales de profesores de la educación infantil y de los años iniciales de la educación fundamental.

Palabras claves: Educación Básica. Música(s). Pedagogía. Unidocencia.

\section{NOTAS}

1. Através da Lei n. 12/287 de 13 de julho de 2010, o parágrafo do art. 26 passou a ser acrescido da orientação "[...] especialmente em suas expressões regionais [...]", passando a vigorar na forma citada no parágrafo. 
2. A Comissão de Educação da Câmara dos Deputados aprovou proposta que estabelece como disciplinas obrigatórias da educação básica as artes visuais, a dança, a música e o teatro. O texto altera a Lei de Diretrizes e Bases da Educação Nacional (LDB 9.394/96), que, atualmente, entre os conteúdos relacionados à área artística, prevê a obrigatoriedade somente do ensino da música. Foi aprovado o substitutivo do relator, deputado Raul Henry (PMDB-PE), ao Projeto de Lei n. 7.032/10, do Senado. O texto original determinava a inclusão da música, das artes plásticas e das artes cênicas no currículo das escolas do ensino fundamental. Consulta em: http:// www2.camara.leg.br/camaranoticias/noticias/EDUCACAO-E-CULTURA/456284-EDUCACAO-APROVA-DANCA-E-TEATRO-COMO-DISCIPLINAS-OBRIGATORIAS-DO-ENSINO-BASICO.html

\section{REFERÊNCIAS}

BARROS, M. de. Memórias inventadas: a infância. São Paulo: Planeta, 2003.

BARUCH, S. Ética. Tradução e notas de Tomaz Tadeu. Belo Horizonte: Autêntica, 2007.

BELLOCHIO, C. R. A formação musical de professores da infância no ensino superior: alguns pressupostos e desafios. In: TRAVERSINI, C. et al. (Org.). Trajetórias e processos de ensinar e aprender: práticas e didáticas. 1. ed. Porto Alegre: EdiPUCRS, v. 2, p. $217-$ $230,2008$.

A educação musical na formação inicial e nas práticas educativas de professores unidocentes: um panorama da pesquisa na UFSM. In: REUNIÃO ANUAL DA ASSOCIAÇÃO NACIONAL DE PÓS-GRADUAÇÃO E PESQUISA EM EDUCAÇÃO, 30, 2007, Caxambu, MG. Anais... Caxambu: ANPED, 2007. Disponível em: <http://www. anped.org.br>. Acesso em: jan. 2009.

. Educação musical: olhando e construindo na formação e ação dos professores. Revista da ABEM, Porto Alegre, n. 6, p. 41-47, 2001.

A educação musical nas séries iniciais do ensino fundamental: olhando e construindo junto às práticas cotidianas do professor. Tese (Doutorado em Educação) - Universidade Federal do Rio Grande do Sul, Porto Alegre, 2000.

BELLOCHIO, C. R.; FIGUEIREDO, S. L. Entre a formação e as práticas musicais em sala de aula: discutindo algumas questões com professoras não especialistas em Música. Música na Básica, Porto Alegre, ABEM, 2009.

BRASIL. Lei n. 9394/96, 20 de dezembro de 1996. Estabelece as diretrizes e bases da educação nacional. Brasília: Diário Oficial da União, v. 248, p. 27833-27841, 23 dez. 1996. Seção 1.

. Diretrizes curriculares para o curso de Pedagogia, resolução CNE/CP n. 1, de 15 de maio de 2006. Disponível em: <http://portal.mec.gov.br/cne/arquivos/pdf/ rcp01_06.pdf>. Acesso em: jun. 2009. 
Lei de Diretrizes Bases da Educação. Lei n. 11.769, de 18 de maio de 2008. Disponível em: <http://www.planalto.gov.br/ccivil_03/_Ato2007-2010/2008/Lei/ L11769.html>. Acesso em: abr. 2009.

CAMBI, F. História da Pedagogia. São Paulo: Ed. Unesp, 1999.

CORAZZA, S. M. Os cantos de Fouror: escrileitura em filosofia-educação. Porto Alegre: Sulina, Ed. UFRGS, 2008.

DELEUZE, G.; GUATTARI, F. Mil Platôs - capitalismo e esquizofrenia, v. 1. Tradução de Aurélio Guerra e Célia Pinto. Rio de Janeiro: Editora 34, 1995.

DELEUZE, G. Conversações. Tradução de Peter Pal Pelbart. São Paulo: Editora 34, 1992.

FERNANDES, C. B. ; CUNHA, M. I. Formação de professores: tensão entre discursos, políticas e teorias e práticas. InterAção, Goiânia, v. 38, n. 1, p. 51-55, 2013.

FOUCAULT, Michel. Verdade, poder e si mesmo. In: . Ditos e escritos V: ética, sexualidade e política. Rio de Janeiro: Forense Universitária, 2006.

HARNONCOURT, N. O discurso dos sons: caminhos para uma nova compreensão musical. Tradução de Marcelo Fagerlande. Rio de Janeiro: Jorge Zahar, 1998.

LINO, D. L. Barulhar: uma escuta sensível da música nas culturas da infância. Tese (Doutorado em Educação) - Programa de Pós-Graduação em Educação da Universidade Federal do Rio Grande do Sul, Porto Alegre, 2008.

NIETZSCHE, F. O Nascimento da tragédia ou helenismo e pessimismo. Tradução, notas e posfácio de J. Guinsburg. São Paulo: Companhia das Letras, 2007.

SEVERINO, A. J. Fundamentos ético-políticos da educação no Brasil de hoje. In: LIMA, J. C. F. e NEVES, L. M.W. (Orgs.). Fundamentos da educação escolar do Brasil contemporâneo. Rio de Janeiro: Fiocruz, 2009.

STRAVINSKY, I. Poética musical em 6 lições. Tradução de Luiz Paulo Horta. Rio de Janeiro: Jorge Zahar, 1996.

Cláudia Ribeiro Bellochio é bacharel em Música, licenciada em Pedagogia, mestre em Educação pela UFSM, doutora em Educação pela UFRGS. Editora da Revista Educação UFSM, Presidente do conselho editorial da Revista da ABEM, conselheira da ABEC.

E-mail: claubell@terra.com.br

Eduardo Guedes Pacheco é bacharel em Percussão e mestre em Educação pela UFSM. Doutor em Educação pela UFRGS. Professor da UERGS. Coordenador Pedagógico da Associação CUÍCA - Cultura, Inclusão, Cidadania e Artes.

E-mail: edupandeiro@gmail.com 